\title{
ATORES SOCIAIS EM ESPAÇOS DE AMPLIAÇÃO DA DEMOCRACIA: AS REDES SOCIAIS EM PERSPECTIVA
}

\author{
Joana Tereza Vaz de Moura
}

\author{
Marcelo Kunrath Silva
}

\begin{abstract}
RESUMO
O Brasil assistiu, ao longo das décadas de 1980 e 1990, à proliferação de fóruns, conselhos, comitês e parcerias que instituíram, nos diversos níveis de governo e nas mais variadas áreas de atuação do Estado, canais institucionais abertos para a expressão política de atores e segmentos da sociedade civil. Entretanto, a literatura que analisa esse processo tem, em grande medida, adotado uma visão dicotômica e normativa da sociedade civil. Observa-se a necessidade de ruptura com uma apreensão estática e substancialista da sociedade civil, a partir da adoção de um enfoque processual e relacional que permita analisar o processo de construção dos atores sociais na sua relação com outros atores e instituições (em especial, com o campo político-institucional). Assim, este é um trabalho de proposição teórico-metodológica e não de apresentação de resultados de pesquisa, tendo como objetivo problematizar a literatura que trabalha com uma abordagem normativa e estilizada da sociedade civil e propor a incorporação da abordagem das redes de políticas à discussão e análise dos processos de formação e atuação dos atores da sociedade civil e, mais especificamente, de como esses processos relacionam-se com os espaços institucionais de participação. Como instrumento de operacionalização metodológica da abordagem das redes de políticas, propõe-se o emprego da análise de redes sociais, para apreender o processo de construção e atuação dos atores sociais a partir de seu pertencimento a um espaço relacional e dinâmico, no qual se inserem atores com distintas vinculações institucionais (sociedade civil, Estado, mercado).
\end{abstract}

PALAVRAS-CHAVE: participação; análise de redes sociais; enfoque processual e relacional; sociedade civil.

\section{INTRODUÇÃO}

A redemocratização brasileira, a partir da segunda metade da década de 1970, teve como um de seus fatores propulsores e, ao mesmo tempo, como um de seus resultados mais significativos um intenso e complexo processo de transformação do tecido associativo do país, que se expressou na "entrada em cena de novos personagens", conforme o título do já clássico trabalho de Eder Sader (1988). Esse processo, que confere especificidades à redemocratização brasileira no âmbito das transições nos países do Cone Sul (STEPAN, 1985), foi um dos fatores centrais na conformação do contexto político-institucional posterior ao fim da ditadura militar, marcado por iniciativas de descentralização e pela criação de espaços institucionais abertos à participação e à representação política da sociedade civil. Assim, assistiu-se, ao longo das décadas de 1980 e 1990, à proliferação de fóruns, conselhos, comitês e parcerias, que instituíram, nos diversos níveis de governo e nas mais variadas áreas de atuação do Estado, canais institucionais abertos para a expressão política de atores e de segmentos da sociedade civil (SILVA, 2003).

Essa proliferação de espaços institucionais de participação foi acompanhada de diversas reflexões teóricas nas Ciências Sociais, especialmente no que se refere ao papel desempenhado pela sociedade civil na consolidação e no aprofundamento da democracia (AVRITZER, 1994; 2003; COSTA, 1997; GOHN, 1997; SANTOS, 2002).

Essa literatura, no entanto, tem sido crescentemente problematizada (LAVALLE, 2003; SILVA, 2006) por apresentar uma abordagem normativa e estilizada da sociedade civil, que limita sua capacidade de apreensão e análise da complexidade da "sociedade civil realmente existente" e das suas relações com os atores e as instituições do campo político-institucional (entre elas, os espaços institucionais de participação). 
Um aspecto, em especial, parece demandar instrumentos teórico-metodológicos mais qualificados, capazes de fornecer marcos interpretativos e gerar informações que permitam um tratamento analítico mais adequado à complexidade que caracteriza os objetos empíricos em foco: observase a necessidade de ruptura com uma apreensão estática e substancialista da sociedade civil, a partir da adoção de um enfoque processual e relacional que permita analisar o processo de constituição dos atores sociais na sua relação com outros atores e instituições, em especial, com o campo político-institucional.

Como uma alternativa teórica para responder a essa demanda, este artigo propõe a incorporação do conceito de "redes de políticas" à discussão e à análise dos processos de constituição e de atuação dos atores da sociedade civil e, mais especificamente, de como esses processos relacionam-se com os espaços institucionais de participação que, ao longo da última década, foram implantados em quase todos os setores de políticas públicas do Estado brasileiro.

Por sua vez, como instrumento de operacionalização metodológica do enfoque das redes de políticas, propõe-se o emprego da análise de redes sociais (ARS), que nos últimos anos passou a fazer parte da pauta metodológica dos estudos sobre organizações, movimentos sociais, participação e gestão pública, bem como das inovações institucionais a eles associadas (MARQUES, 1999; DIANI \& MCADAM, 2003; LAVALLE, CASTELLO \& BICHIR, 2006; SILVA, 2006). Argumenta-se que a análise da sociedade civil e dos processos de participação por meio da ARS fornece ferramentas metodológicas para romper com a visão substancialista da sociedade civil, ao apreender o processo de constituição e atuação dos atores sociais a partir de seu pertencimento a um espaço relacional e dinâmico, no qual se inserem atores com distintas vinculações institucionais (sociedade civil, Estado, mercado). Além disso, a possibilidade que a ARS oferece - apreender os padrões de relações entre os atores sociais e os atores e instituições do campo político-institucional, bem como suas mudanças ao longo do tempo -, constitui um importante instrumento para a operacionalização metodológica do conceito de redes de políticas.

Para desenvolver essa perspectiva, a próxima seção deste artigo apresentará uma reflexão introdutória sobre a literatura nacional focada nos temas da participação e da sociedade civil, identificando problemas e limites na forma como essa literatura trabalha a relação entre organizações da sociedade civil e Estado. Em seguida, far-se-á uma breve apresentação do conceito de redes de políticas e suas contribuições analíticas ao estudo da sociedade civil e das experiências participativas, focalizando a ARS e buscando demonstrar suas potencialidades para apreender a complexidade, a diversidade e a dinamicidade das relações estabelecidas entre os atores inseridos nos espaços institucionais de participação. Finalmente, algumas reflexões serão feitas para a elaboração de uma possível agenda de pesquisa sobre os novos espaços de participação e representação a partir da incorporação do enfoque das redes de políticas.

\section{OS NOVOS ESPAÇOS DE PARTICIPAÇÃO E OS LIMITES DOS MODELOS TEÓRICOS}

A multiplicação de espaços de participação social nos últimos anos no Brasil tem sido acompanhada de diversas reflexões teóricas nas Ciências Sociais, especialmente no que se refere ao papel desempenhado pela sociedade civil como peçachave na construção e no aprofundamento da democracia ${ }^{1}$.

Entretanto, a literatura que trata da relação entre as organizações da sociedade civil e os atores e instituições político-administrativas em grande medida ainda se tem mostrado insuficiente para entender o processo relacional existente entre eles, por apresentar uma visão marcadamente normativa, estática, substancialista e dicotômica.

No debate internacional, especialmente nos anos 1990, diversos autores apostaram no fortalecimento da sociedade civil e na sua capacidade emancipatória ${ }^{2}$. Apesar de haver diferentes atri-

1 No livro Civil Society and Political Theory, Cohen e Arato (1994) sistematizam a construção teórica do conceito de sociedade civil, de modo a lhe atribuir o papel central de transformação social. Por outro lado, diversos autores enfatizam a necessidade de aprofundar a democracia aumentando a presença da sociedade civil em formas alternativas de representação, principalmente por meio da criação de espaços em que ela possa se manifestar (AVRITZER, 1994; 2003; COSTA, 1997; GOHN, 1997; SANTOS, 2002).

2 Os movimentos sociais, antes privilegiados como referência para as transformações sociais, praticamente desa- 
buições às potencialidades e às funções da sociedade civil, observa-se um relativo consenso sobre o conteúdo do conceito (PINTO, 2005), em grande medida, a partir da influência de autores como Jean Cohen e Andrew Arato. De acordo com esses autores, a sociedade civil pode ser vista como um conjunto de organizações voluntárias que reúnem pessoas fora dos marcos do Estado e do mercado (COHEN \& ARATO, 1994). Os autores encontram alicerce no pensamento de Jürgen Habermas e adotam uma concepção tripartite da sociedade, na qual são diferenciados os âmbitos sistêmicos (mercado e político-administrativo) e o "mundo da vida”. Articulando essa concepção com o longo debate em torno do conceito de sociedade civil, os autores chegam à formulação segundo a qual "[...] civil society represents a sphere other than an even opposed to the state. All include, almost always unsystematically associations, and forms of independent public expression"3 (idem, p. 74).

Em um artigo escrito em 2003, Jean Cohen atenta para o fato de o conceito de sociedade civil englobar um campo de organizações altamente diversificado, incluindo desde empreendimentos cívicos, associações voluntárias e organizações sem fins lucrativos até redes mundiais, organizações não-governamentais, grupos de defesa dos direitos humanos e movimentos sociais transnacionais. Nesse sentido, a autora problematiza a suposta virtuosidade dada à categoria "sociedade civil" e ao discurso que a define como "fonte principal da solidariedade e da integração social” (COHEN, 2003, p. 419). Entretanto, a separação dicotômica entre sociedade e Estado permanece presente. Nas palavras da autora, "Entendo a sociedade civil como uma esfera de interação social diferenciada da economia e do Estado, composta de três parâmetros analiticamente distintos: pluralidade, publicidade e privacidade. A moderna sociedade civil 'autônoma'

parecem do debate teórico das Ciências Sociais brasileiras nos anos 90, para dar lugar à sociedade civil, que passa a ocupar o centro das reflexões e análises dos autores voltados ao estudo das relações entre democratização e atuação dos atores sociais (LAVALLE, CASTELLO \& BICHIR, 2004).

3 “....] A sociedade civil representa uma outra esfera que uma oposta ao Estado. Tudo incluído, quase sempre associações assistemáticas e formas de expressão pública independente” (nota do revisor). nasceu de processos de constituição e mobilização independente" (idem, p. 422; grifos no original).

No âmbito das Ciências Sociais brasileiras, a análise das relações entre Estado e sociedade civil apresenta uma trajetória distinta daquela observada em outros países. Em vez do predomínio de abordagens que reduziam o Estado e suas políticas a uma "emanação" de demandas e interesses de atores sociais e/ou do mercado, como identificado e criticado por Evans, Rueschemeyer e Sckocpol (1985), no Brasil predominaram perspectivas que conferiam uma primazia ao Estado enquanto ator protagonista na estruturação da vida social e/ou do seu desenvolvimento (STEPAN, 1985). Ou seja, seguindo a crítica de Sader e Paoli (1986), pode-se identificar o predomínio de uma concepção "estatista”, a qual tendia a reservar ao Estado a capacidade de iniciativa e de condução da dinâmica sócio-política e/ou da modernização do país, cabendo aos atores não-estatais, particularmente aqueles constituídos entre os segmentos mais pauperizados e oprimidos da sociedade, um papel de coadjuvantes destituídos de agência.

Em oposição a essa concepção, observa-se, a partir do final dos anos 1970, aquilo que Nun (1989) apreendeu como a “rebelião do coro”. Ou seja, atores sociais tradicionalmente marginalizados da cena política passam não apenas a ocupar o “palco", mas, principalmente, são objeto de uma ressignificação a partir de modelos interpretativos que os valorizam e, no limite, põe-nos como protagonistas da mudança de um país caracterizado por profundas desigualdades e dominações.

Essa ressignificação, característica da expressiva literatura sobre movimentos sociais produzida no período, foi marcada por uma radicalização da distância entre Estado e atores da sociedade que, no limite, passou a ser tratada como uma relação de contradição -, a qual levou a um tratamento dicotômico e substancialista desses dois pólos: dicotômico na medida em que a visão de uma sociedade forjada por um Estado "todo-poderoso" foi substituída pela visão de uma sociedade que, "de costas para o Estado" (EVERS, 1983), auto-organizava-se de maneira espontânea e autônoma; substancialista pelo fato de que o Estado e a sociedade civil (em que surgiu do processo de auto-organização social) não só se constituem e operam de maneira não-relacional como ainda são dotados de um conjunto de qualidades que passam a ser tomadas como inerente às suas 
“naturezas”. Nessa perspectiva, Estado e sociedade civil são apreendidos como blocos homogêneos, marcados por características contrastantes e contrapostas de maneira maniqueísta: enquanto o Estado é corrupto, violento, autoritário, conservador, a sociedade civil é ética, democrática, progressista, universalista.

Por um lado, é certo, essa guinada interpretativa, profundamente vinculada ao contexto ditatorial, propiciou uma perspectiva de análise que ampliou significativamente a compreensão dos processos políticos. Como destaca Telles (1988, p. 281), foi por meio da imagem de externalidade e positividade da sociedade frente ao Estado, “que pudemos pensar a política como algo que não se reduz a um único espaço, prefixado e determinado como lugar do Estado e das relações institucionalizadas de poder”. Ou seja, ao situar no pólo estatal uma negatividade absoluta, o pensamento dicotômico e maniqueísta possibilitou identificar e reavaliar um amplo campo de atores e ações políticas não institucionais dispersas no tecido social.

Por outro lado, no entanto, tal visão encobriu tanto a apreensão e a análise da complexidade e heterogeneidade do Estado e da sociedade civil quanto os profundos vínculos e interdependências existentes entre a configuração do campo político-institucional e a conformação do tecido associativo $^{4}$

Tais limitações tenderam a reproduzir-se no modelo de interpretação predominante nas reflexões sobre a sociedade civil, nos anos 1990, uma vez que esse modelo partia do pressuposto e da defesa normativos da necessidade de uma separação entre a sociedade civil que surgia dos processos autônomos de organização no âmbito do "mundo da vida" e os atores e instituições do sistema político-administrativo e do mercado. Assim, apreendida como solidária, orientada para o interesse geral, originada da associação espontâ-

\footnotetext{
4 Uma exceção, no contexto dos anos 1980, foi o trabalho de Boschi (1987), cuja crítica a uma apreensão "antiinstitucionalista” dos processos de organização social se expressa na seguinte afirmação: "As instituições organizam a experiência diária dos indivíduos, dando forma aos ressentimentos e definindo as demandas e metas de ação. Também são um determinante implícito das formas eventualmente assumidas pelo protesto, no sentido de que é a vida institucional que agrega e dispersa as pessoas" (idem, p. 19).
}

nea, dentre outras características, a sociedade civil passou a ser o foco das propostas e das análises de arranjos institucionais participativos que marcaram a redemocratização brasileira.

Na medida em que a existência de uma efetiva democracia depende da articulação entre a esfera político-institucional e a esfera societária, por meio da mediação da esfera pública, na qual demandas, interesses e problemas sociais conseguem expressar-se e, de alguma forma, orientar a atuação dos agentes e instituições político-administrativas, torna-se imprescindível a existência de atores sociais capazes de organização e atuação autônomas. Como destaca Costa (1994, p. 44), “a sociedade civil, com seu conjunto de associações voluntárias, independentes do sistema econômico e político-administrativo, absorve, condensa e conduz de maneira amplificada para a esfera pública os problemas emergentes nas esferas privadas, no mundo da vida".

Ou seja, são as formas de associativismo civil, na medida em que tiverem capacidade e autonomia, que garantirão que o fluxo de influências oriente-se da sociedade para as instituições político-administrativas, garantindo o controle e a abertura destas para os interesses societários, e não o contrário, com a subordinação da sociedade e seus atores aos interesses e à racionalidade da esfera político-administrativa. Desse ponto de vista, acredita-se na lógica democratizante própria das organizações da sociedade civil que contrasta com as lógicas burocrática do Estado e excludente do mercado.

Baseados nesses pressupostos, diversos pesquisadores voltados para o tema da participação social e das relações entre sociedade civil e Estado no Brasil têm centrado suas análises na sociedade civil e na hipótese de que, quanto maior a sua participação nos processos decisórios, maiores a possibilidade e a capacidade de as políticas públicas incorporarem as reivindicações e as propostas dos segmentos subalternos e, assim, diminuírem a desigualdade social e a pobreza dos países em desenvolvimento ${ }^{5}$ (AVRITZER, 1994; 2003; COSTA, 1997; SANTOS, 2002).

\footnotetext{
${ }^{5}$ Recentemente, alguns autores fazem críticas aos teóricos da democracia participativa, por estes ignorarem o papel da representação nos arranjos institucionais participativos; ver, dentre eles, Warren (2005), Lavalle, Houtzager e Castello (2006a).
} 
Assim, o centro dessa perspectiva da sociedade civil é uma leitura dual e normativa das relações entre Estado (autoritário) e sociedade (democrática) (HOUTZAGER, LAVALLE \& ACHARYA, 2004). Na verdade, trata-se de uma análise estilizada e homogênea da sociedade civil, em que os atores sociais são tidos como pilares da democratização, enquanto o Estado, igualmente homogêneo, ameaça a sociedade civil por meio das suas estratégias de "colonização".

Esse dualismo que marca grande parte da literatura que procura estudar os processos participativos - sociedade civil versus Estado não consegue dar conta de uma relação que é constitutiva de ambos os "pólos" e, em muitos aspectos, dos limites fluidos e imprecisos que separam sociedade civil e Estado. Em outras palavras, essa literatura encontra-se fragilizada para identificar e analisar a permeabilidade (MARQUES, 2004) intrínseca à sociedade civil e ao Estado, como também as relações entre atores sociais e atores e instituições político-administrativas.

\section{ROMPENDO A DICOTOMIA: OS ATORES SOCIAIS E AS REDES DE POLÍTICAS}

Nos últimos anos, buscando superar essas limitações analíticas da perspectiva dominante na literatura brasileira voltada ao estudo das experiências de participação e de representação institucional da sociedade civil, pesquisadores (DAGNINO, 2002; LAVALLE, 2003; DAGNINO, OLVERA \& PANFICHI, 2006; SILVA, 2006) vêm buscando modelos teórico-metodológicos mais adequados à complexidade da sociedade civil e de suas relações com o campo político-institucional. Um conceito particularmente fértil para tratar desse tema mas, curiosamente, pouco incorporado e utilizado pelos cientistas sociais brasileiros que pesquisam a sociedade civil e/ou as experiências de participação, é o de rede de políticas. Um dos poucos empregos da abordagem da rede de políticas no Brasil encontra-se nos trabalhos de Marques (1999); outros dois exemplos recentes de utilização dessa abordagem no estudo sobre políticas públicas no Brasil encontram-se em Carpim (2005) e Müller (2006).

O conceito de redes de políticas começou a ser elaborado durante a década de 1970 (SKOGSTAD, 2005) e, mais recentemente, passou a ser amplamente utilizado nos estudos sobre a relação entre Estado e atores não-estatais dos mais diferentes tipos envolvidos nos processos de formulação e/ou implantação de políticas públicas, prevalecendo, no entanto, a análise das relações entre Estado e atores do mercado. Segundo Kenis e Schneider, "A policy network is described by its actors, their linkages and its boundary. It includes a relatively stable set of mainly public and private corporate actors. The linkages between the actors serve as channels for communication and for the exchange of information, expertise, trust and other policy resources. The boundary of a given policy network is not in the first place determined by formal institutions but results from a process of mutual recognition dependent of functional relevance and structural embeddedness" 6 (KENIS \& SCHNEIDER, 1989, p. 14; grifo no original).

Conforme a definição acima, observa-se que o conceito de redes de políticas apresenta-se como um conceito "aberto". Ou seja, apesar de destacar e focalizar as relações estabelecidas entre Estado e atores não-estatais, não há uma definição prévia da configuração de tal relação. Nesse sentido, o conceito de redes de políticas apresenta-se como um conceito que busca apreender diferentes padrões de relação entre Estado e atores nãoestatais, além de analisar como tais padrões influenciam a conformação e/ou os resultados de determinada política (JORDAN \& SCHUBERT, 1992, p. 10-11).

Como resultado dessa identificação de diferentes padrões de relação entre os atores inseridos e atuantes nas redes de políticas, a literatura internacional sobre o tema tem-se caracterizado pela formulação e pelo emprego de diversas tipologias, que buscam dar conta das inúmeras possibilidades empíricas de conformação das redes: estatismo, clientelismo, pluralismo, triângulos de ferro, issue networks ${ }^{7}$, corporativismo estatal,

6 "Uma rede de políticas é descritível por seus atores, por seus vínculos e por seus limites. Ela inclui um conjunto relativamente estável de atores corporativos principalmente públicos e privados. Os vínculos entre os atores servem como canais para a comunicação e para a troca de informações, perícias, confiança e outros recursos da política pública. O limite de uma dada rede de política não é o primeiro lugar determinado pelas instituições formais, mas resulta de um processo de reconhecimento mútuo dependente da relevância funcional e da inclusão [embeddedness] funcional” (N. R.).

7 “Redes temáticas”, em inglês, no original (N. R.). 
corporativismo setorial, entre outros (WAARDEN, 1992).

Tal proliferação de denominações, por um lado, tem permitido um significativo enriquecimento na identificação e na análise dos distintos padrões de relação entre atores estatais e não-estatais. Por outro lado, no entanto, tem apresentado o risco de uma confusão terminológica, devido à ausência de critérios comuns de classificação. Assim, autores utilizam denominações distintas para tratar dos mesmos fenômenos empíricos ou, ao contrário, usam denominações similares para classificar fenômenos empíricos distintos (idem, p. 49).

Na medida em que o conceito de redes de políticas apresenta um caráter intrinsecamente relacional (EMIRBAYER, 1997), destacando tanto a influência dos atores e instituições estatais sobre a conformação e expressão dos interesses societais e/ou do mercado, quanto a participação dos atores sociais e/ou mercantis na definição das ações do Estado, ele apresenta-se como um instrumento analítico fértil para romper com o pensamento dicotômico e substancialista identificado anteriormente na literatura brasileira que analisa a relação entre sociedade civil e Estado. Nesse sentido, uma das potencialidades da abordagem das redes de políticas é que, ao focalizar as relações entre os atores, ela possibilita uma perspectiva de análise que rompe as fronteiras institucionais e apreende como atores posicionados em diferentes contextos institucionais relacionam-se e, a partir da configuração desses relacionamentos, são produzidos determinados resultados em termos de políticas públicas. Segundo Nyland, "Policy networks or communities are concepts that indicate the connections and interactions between state and players outside of the states with regard to policymaking. They challenge the primacy of the state by identifying the inclusion of external parties (those outside of the state) in the formal policy process"8 (NYLAND, 1995, p. 197).

Essa perspectiva relacional - e não meramente institucional - possibilita apreender padrões

\footnotetext{
8 "Redes ou comunidades de políticas são conceitos que indicam as conexões e as interações entre estados e atores externos aos estados a respeito da formulação das políticas públicas. Elas desafiam o primado do Estado ao identificarem a inclusão de partes externas (aquelas que estão fora do Estado) no processo formal de elaboração de políticas” (N. R.).
}

muito mais complexos de relações, que vão além das tradicionais fórmulas dicotômicas (sociedade versus Estado; mercado versus Estado) ou mesmo tripartites (sociedade civil versus mercado versus Estado; Estado versus mercado versus terceiro setor). A partir do conceito de redes de políticas observa-se que os padrões de alianças e conflitos podem - ou, mais corretamente, tendem - a atravessar as fronteiras institucionais, reunindo atores com distintas inserções institucionais, mas que atuam conjuntamente em determinado setor de política pública. Essa ampliação do foco de análise é destacada por Hanf (apud JORDAN \& SCHUBERT, 1992, p. 11), para quem "the term 'network' merely denotes, in a suggestive manner, the fact that policy making includes a large number of public and private actors from different levels and functional areas of government and society"9.

Além dessa "complexificação" dos atores e de suas relações, a abordagem das redes de políticas também possibilita uma apreensão da diversidade de configurações de relações entre atores estatais e não-estatais em distintos setores de políticas. Ou seja, em função da complexificação da sociedade e do Estado, haveria uma tendência de "setorialização" das políticas públicas e, assim, uma diferenciação na conformação das redes de políticas em cada setor.

Isso significa que, em um mesmo contexto, é possível observar padrões diversos de relações entre atores estatais e não-estatais, rompendo com uma apreensão do Estado, da sociedade civil e/ou do mercado como blocos unificados que estabeleceriam relações homogêneas. Um desdobramento dessa ruptura é a abertura para identificar e analisar as diferenciações em termos dos atores politicamente relevantes em cada setor de política e as relações estabelecidas pelos mesmos. Dependendo da configuração da rede do setor, é possível observar variações significativas não apenas em termos da composição da rede, mas também na estruturação das relações entre os atores que a compõem.

Por fim, a abordagem das redes de políticas possibilita focalizar as complexas e dinâmicas re-

9 “O termo 'rede' meramente denota, de uma forma sugestiva, o fato de que a formulação de políticas públicas inclui um grande número de atores públicos e privados, provenientes de diferentes níveis e de áreas funcionais do Estado e da sociedade" (N. R.). 
lações estabelecidas pelos atores em um determinado setor de política, identificando tanto as alianças constituídas entre os atores que compartilham determinados interesses, posições e/ou propostas, quanto os conflitos entre grupos orientados por diferentes intencionalidades e concepções da política. A respeito dessas divisões internas, um conceito desenvolvido no âmbito das discussões sobre redes de políticas é o de "comunidade de política”. Apesar das diferenças no emprego desse conceito (SKOGSTAD, 2005), destaca-se sua utilização para diferenciar os subgrupos dentro de uma determinada rede de política que apresentam concepções e interesses distintos sobre essa rede. Cada subgrupo constituiria, assim, uma comunidade da política; as relações e o equilíbrio de poder que estabelecem definiriam a configuração e a dinâmica da rede da política. No caso de redes hegemonizadas por uma determinada concepção, a comunidade tenderia a apresentar a conformação da própria rede.

A abordagem da rede de políticas tem sido utilizada a partir de diferentes objetivos de análise, constituindo um campo de estudos dinâmico e diversificado. Conforme Tatcher (1998), a abordagem das redes de políticas tanto pode ser empregada como instrumento de caracterização e diferenciação de padrões de relação entre Estado e atores não-estatais, em um sentido mais descritivo e classificatório, quanto pode ser utilizada na tentativa de construir explicações sobre determinados processos empíricos. Neste último caso, a configuração das redes tanto pode ser o fator explicativo de determinado(s) aspecto(s) que esteja(m) sendo investigado(s) quanto pode ser o objeto a ser explicado a partir dos efeitos de outro(s) fator(es).

Um importante recurso que tem sido utilizado pelos estudos das redes de políticas é a metodologia de análise de redes sociais (WASSERMAN \& FAUST, 1994 $)^{10}$. Essa metodologia, ao enfocar os atores (que podem ser indivíduos, grupos, or-

\footnotetext{
10 É necessário fazer uma diferenciação entre a abordagem das redes de políticas e a metodologia da ARS. Esta última propõe-se a uma identificação das características estruturais das redes sociais a partir de um conjunto de indicadores voltados à apreensão e formalização dos padrões de relações entre os atores. A abordagem da rede de políticas, por sua vez, pode recorrer aos recursos metodológicos oferecidos pela ARS, como também pode ser operacionalizada por meio de outros procedimentos metodológicos.
}

ganizações, empresas, Estados etc.) e suas relações, vem construindo ao longo do tempo um conjunto de indicadores e medidas que permitem apreender e analisar de maneira bastante qualificada os padrões de estruturação daquelas relações e, assim, das redes formadas pelos atores. Como destaca Steiner (2006, p. 77), “A análise estrutural [denominação da ARS na Sociologia anglosaxônica] modela os sistemas de vínculos que existem entre os atores e delineia as características da rede por meio de um conjunto de medidas".

De acordo com os pressupostos subjacentes à ARS, a configuração das relações entre os atores constitui uma estrutura que delimita um campo de possibilidades para a e de constrangimentos à constituição e atuação dos atores, rompendo com perspectivas atomistas que abordam os atores de maneira descontextualizada e, ao mesmo tempo, com perspectivas estruturalistas que colocam os atores como executores de determinações de estruturas que lhes existiriam prévia e externamente. Segundo Marques (2006, p. 19), "O sentido de estrutura para a análise de redes, portanto, não é o mesmo das análises estruturalistas anteriores, pois no caso das redes o formato e o conteúdo são levantados dedutivamente pelo trabalho empírico, no que Tilly [...] denominou [de] estruturalismo a posteriori”.

A partir dos instrumentos metodológicos fornecidos pelas ARS, a abordagem das redes de políticas tem conseguido ir além da utilização da noção de rede como mera metáfora, produzindo análises que apreendem rigorosa e detalhadamente a forma e o conteúdo das relações estabelecidas entre os atores e suas implicações do ponto de vista das políticas públicas.

\section{ANÁLISE DE REDES E EXPERIÊNCIAS DE PARTICIPAÇÃO INSTITUCIONAL DOS ATORES DA SOCIEDADE CIVIL}

Conforme destacado anteriormente, a abordagem das redes de políticas e a metodologia de ARS apresentam-se como recursos valiosos para a ruptura com as abordagens dicotômicas e substancialistas da relação entre sociedade civil e Estado. Nos estudos sobre processos de participação dos atores da sociedade civil em espaços institucionais, em especial, esses recursos teórico-metodológicos parecem oferecer alternativas de análise que permitem superar algumas lacunas e limites da literatura indicados anteriormente neste artigo. 
O pressuposto da existência de uma relação de interdependência entre os processos associativos no âmbito societário e a configuração do campo político-institucional, ao lado do desenvolvimento de instrumentos metodológicos para apreender a forma e o conteúdo desta relação por meio da ARS, possibilitam o desenvolvimento de uma abordagem não dicotômica, que seja capaz de apreender e analisar a fundamentação relacional tanto do associativismo quanto dos espaços institucionais de participação ${ }^{11}$.

Em primeiro lugar, a partir dessa abordagem é possível analisar os efeitos de diferentes padrões de relações entre atores sociais e políticoinstitucionais ou, ainda, de suas mudanças ao longo do tempo, sobre a conformação das práticas associativas. Mais especificamente, essa abordagem permite analisar os efeitos da introdução de inovações institucionais participativas (tais como conselhos de políticas públicas e orçamentos participativos) sobre as relações entre atores sociais e político-institucionais e, assim, sobre a estruturação do tecido associativo.

A fertilidade analítica dessa abordagem relacional pode ser observada no trabalho de Abers (2000), que enfoca os efeitos da mudança dos padrões de relações entre atores sociais e atores do governo municipal de Porto Alegre sobre as práticas associativas, a partir da introdução do orçamento participativo nessa cidade, em 1989. Segundo a autora, o padrão predominante até o final dos anos 1980, denominado de clientelista, abria poucas oportunidades à organização autônoma da sociedade civil. Com a introdução de um espaço de participação institucional como o orçamento participativo, ao lado da atuação de atores governamentais no sentido de estimular processos de organização e mobilização sociais, alterou-se significativamente o padrão de relação entre estes atores e os atores sociais, na medida em que estes últimos passaram a ser incluídos como atores politicamente relevantes nos processos de decisão

\footnotetext{
11 Apesar dessas potencialidades, praticamente inexistem pesquisas que utilizam a abordagem das redes de políticas e a ARS como ferramentas analíticas para o estudo das experiências participativas e das relações entre sociedade civil e Estado. Neste sentido, nesta seção são abordados alguns trabalhos que, mesmo sem a aplicação direta destas ferramentas, empregam perspectivas relacionais de análise que se aproximam daquela proposta pelos autores do artigo, exemplificando os ganhos analíticos desta proposta.
}

sobre a distribuição dos recursos públicos na cidade. Essa nova estrutura de relações modificou o contexto de atuação dos atores sociais, abrindo novas oportunidades (e, também, novos constrangimentos).

Em segundo lugar, essa abordagem possibilita observar os efeitos de configurações associativas prévias sobre a dinâmica dos espaços institucionais de participação e a estrutura de relações entre os atores que deles participam. Ou seja, na medida em que se rompe com uma perspectiva substancialista da sociedade civil, abre-se espaço para a identificação e análise do que Baiocchi (2005, p. 20) conceitua como distintas configurações cívicas e, ainda, das oportunidades e constrangimentos que tais configurações estabelecem para a implantação e atuação de espaços institucionais de participação voltados, entre outras coisas, à incorporação de atores sociais aos processos de discussão sobre e/ou decisão de políticas públicas.

Nesse sentido, pesquisas recentes vêm mostrando variações significativas entre as experiências de participação analisadas em função, entre outros fatores, de diferenças na conformação do tecido associativo envolvido. Assim, diferenças na configuração cívica dentro de um mesmo município (BAIOCCHI, 2005), entre municípios (SILVA, 2001; 2003; BORBA \& LÜCHMANN, 2007), entre níveis de governo (CORTÊS, 2004) ou, ainda, entre distintos setores de política (idem), imprimem, em maior ou menor grau, suas marcas na estruturação e no funcionamento dos espaços institucionais de participação.

No entanto, apesar da crescente presença de pesquisas que adotam uma perspectiva relacional, como expresso nos exemplos citados acima, praticamente inexistem estudos no Brasil que explorem sistematicamente a abordagem das redes de políticas e da metodologia de ARS para analisar as configurações associativas e suas relações com o campo político-institucional (e, mais especificamente, com a introdução de inovações institucionais voltadas à participação e à representação da sociedade civil) ${ }^{12}$. Assim, deixam de ser utilizados recursos teórico-metodológicos que,

12 Uma importante exceção é o trabalho de Lavalle, Castello e Bichir (2006). Esse estudo, apesar de sua inovação metodológica e do riquíssimo trabalho empírico, tende, no entanto, a limitar-se a uma caracterização (necessária, ob- 
segundo Emirbayer (1997), constituem o meio mais adequado para operacionalizar uma perspectiva relacional nas Ciências Sociais.

\section{REFLEXÕES FINAIS SOBRE UMAAGENDA DE PESQUISA}

Não existe dúvida sobre a importância dos estudos sobre os espaços institucionais de participação realizados ao longo das últimas duas décadas, os quais levaram à estruturação de um campo produtivo e qualificado no interior das Ciências Sociais brasileiras. Entretanto, como foi identificado no decorrer do artigo, ainda existem importantes lacunas na análise dessas experiências participativas e, particularmente, de como estas têm gerado transformações tanto no âmbito da sociedade civil quanto do campo políticoinstitucional. Estas lacunas, para serem enfrentadas, exigem a construção coletiva de uma vasta agenda de pesquisa, na qual abordagens relacionais e, mais especificamente, a abordagem da rede de políticas e a análise de redes sociais constituem opções teórico-metodológicas promissoras.

Retomando as indicações de Tatcher (1998) apresentadas anteriormente, uma primeira grande potencialidade da abordagem das redes é oferecer uma alternativa analítica que rompe com as apreensões essencialistas e normativamente orientadas, seja da sociedade civil, seja do Estado. Ao propiciar instrumentos teórico-metodológicos para a apreensão da diversidade das formas empíricas apresentadas por esses campos, a abordagem das redes possibilita a identificação e a diferenciação de padrões específicos de configuração dos mesmos e das relações estabelecidas entre eles.

Dessa forma, torna-se possível superar a busca de uma suposta natureza da sociedade civil, do Estado ou, ainda, de suas relações, avançando para a identificação de distintos "tipos" de configurações associativas, campos político-institucionais e regimes Estado-sociedade civil (BAIOCCHI, 2005). A construção de tipologias empiricamente fundamentadas constitui, por sua vez, um passo

viamente) da rede associativa da cidade de São Paulo. A partir deste "mapeamento", os autores apontam uma série de elementos para a construção de uma agenda de pesquisa, os quais vêm ao encontro de grande parte das proposições apresentadas ao longo deste artigo. fundamental e necessário para que esse campo de estudos avance além da justaposição de estudos de casos, viabilizando análises comparativas e, especialmente, a compreensão das significativas variações observadas entre os mesmos.

A partir dessas tipologias torna-se possível, então, passar a um outro nível de análise salientado por Tatcher (1998), que é a elaboração de modelos explicativos para as variações empiricamente identificadas entre os casos investigados. Ou seja, além de permitir identificar os diferentes padrões de relações entre os atores, a abordagem das redes oferece instrumentos analíticos para a elaboração de hipóteses explicativas tanto sobre os fatores causais das diferenças identificadas quanto sobre as implicações dessas diferenças em relação a determinado objeto em estudo. Nesse sentido, por exemplo, padrões de relações previamente existentes (na sociedade civil, no Estado ou entre esses campos) podem constituir-se em fatores causais na explicação de determinados resultados observados na implantação e no funcionamento de canais institucionais com participação e representação social ou, ao contrário, esses padrões podem sofrer influências mais ou menos significativas devido à instituição desses canais.

Nessa busca de elaboração de modelos explicativos, uma vertente que parece ser bastante promissora é o cruzamento entre padrões relacionais e outros fatores causais - tais como atributos dos atores, configurações institucionais, estruturas de posições etc. -, de modo a identificar a fecundidade analítica de diferentes perspectivas teóricas e, ao mesmo tempo, produzir matrizes interpretativas dotadas da complexidade necessária para a análise dos objetos em foco.

Assim, observa-se que o campo de estudos sobre sociedade civil e, mais especificamente, sobre as relações entre os atores sociais e o campo político-institucional ainda apresenta uma ampla agenda de investigação empírica e elaboração teórico-metodológica a ser desenvolvida. É como contribuição para esse desenvolvimento, que possibilite um avanço dos futuros estudos a partir do significativo acúmulo de conhecimento já produzido até o momento, que a abordagem das redes, seja por meio do conceito de redes de políticas, seja por meio da metodologia de análise de redes sociais, parece apresentar-se como instrumento útil e fértil para os pesquisadores brasileiros. 
Joana Tereza Vaz de Moura (joanatereza@gmail.com) é Mestre em Ciências: Desenvolvimento, Agricultura e Sociedade pela Universidade Federal Rural do Rio de Janeiro (UFRRJ) e doutoranda em Ciência Política na Universidade Federal do Rio Grande do Sul (UFRGS).

Marcelo Kunrath Silva (mksilva@ufrgs.br) é Mestre e Doutor em Sociologia pela Universidade Federal do Rio Grande do Sul (UFRGS) e Professor do Departamento de Sociologia e do Programa de PósGraduação em Sociologia da mesma instituição.

\section{REFERÊNCIAS BIBLIOGRÁFICAS}

ABERS, R. 2000. Do clientelismo à cooperação : governos locais, políticas participativas e organização da sociedade civil em Porto Alegre. Cadernos da Cidade, São Paulo, v. 5, n. 7, maio.

AVRITZER, L. (org.). 1994. Sociedade civil e democratização. Belo Horizonte : Del Rey.

2003. O orçamento participativo e a teoria democrática : um balanço crítico. In : AVRITZER, L. \& NAVARRO, Z. (orgs.). A inovação democrática no Brasil. O orçamento participativo. São Paulo : Cortez.

BAIOCCHI, G. 2005. Militants and Citizens : The Politics of Participatory Democracy in Porto Alegre. Palo Alto : Stanford University.

BORBA, J. \& LUCHMANN, L. (orgs.). 2007. Orçamento participativo : análise das experiências desenvolvidas em Santa Catarina. Florianópolis : Insular.

BOSCHI, R. R. 1987. A arte da associação : política de base e democracia no Brasil. São Paulo : Vértice.

CARPIM, T. P. 2005. Políticas públicas e ampliação do capital social em comunidades segregadas : o Programa Santo André Mais Igual. São Paulo. Dissertação (Mestrado em Ciência Política). Universidade de São Paulo.

COHEN, J. 2003. Sociedade civil e globalização : repensando categorias. Dados, Rio de Janeiro, v. 46, n. 3, p. 419-459. Disponível em : http://www.scielo.br/pdf/dados/v46n3/ a01v46n3.pdf. Acesso em : 3.maio.2008.

COHEN, J. \& ARATO, A. 1994. Civil Society and Political Theory. Cambridge, Mass. : Massachusetts Institute of Technology.

CÔRTES, S. 2004. Participação e governança : o impacto de fóruns participatórios sobre a gestão e implementação de políticas públicas. Tra- balho apresentado no XXVIII Encontro da Associação Nacional de Pós-Graduação e Pesquisa em Ciências Sociais, realizado entre 27 e 29 de outubro, em Caxambu (Minas Gerais). Digit.

COSTA, S. 1994. Esfera pública, redescoberta da sociedade civil e movimentos sociais no Brasil. Uma abordagem tentativa. Novos Estudos, São Paulo, n. 38, p. 38-52.

1997. Contextos da construção do espaço público no Brasil. Novos Estudos, São Paulo, n. 47, p. 179-192, mar.

DAGNINO, E. 2002. Sociedade civil, espaços públicos e a construção democrática no Brasil : limites e possibilidades. In : (org.). Sociedade civil e espaços públicos no Brasil. São Paulo : Paz e Terra.

DAGNINO, E.; OLVERA, A. \& PANFICHI, A. (orgs.). 2006. A disputa pela construção democrática na América Latina. São Paulo : Paz e Terra.

DIANI, M. \& MCADAM, D. (eds.). 2003. Social Movements and Networks : Relational Approaches to Collective Action. Oxford : Oxford University.

EMIRBAYER, M. 1997. Manifesto for a Relational Sociology. American Journal of Sociology, Chicago, v. 103, n. 2, p. 281-317, Sept. Disponível em : http:// www.chssp.columbia.edu/events/documents/ Emirbayer.pdf. Acesso em : 3.maio.2008.

EVANS, P.; RUESCHEMEYER, D. \& SKOCPOL, T. (eds.). 1985. Bringing the State Back In. Cambridge : Cambridge University.

EVERS, T. 1983. De costas para o Estado, longe do Parlamento. Novos Estudos, São Paulo, v. 2, n. 1, p. 25-39, abr. 
FERRAZ, A. T. R. 2005. Impactos da experiência conselhista sobre as atividades políticas e organizativas dos movimentos sociais na saúde : o caso do movimento popular de saúde de Campinas-SP. Campinas. Tese (Doutorado em Ciências Sociais). Universidade Estadual de Campinas.

GOHN, M. G. 1997. Teorias dos movimentos sociais. Paradigmas clássicos e contemporâneos. São Paulo : Loyola.

HANNEMAN, R. A. 2001. Introduction to Social Network Methods. Disponível em : http:// www.faculty.ucr.edu/ hanneman/nettext/. Acesso em : 3.maio.2008.

HOUTZAgER, P.; LAVALLE, A. G. \& ACHARYA, A. 2004. Atores da sociedade civil e atores políticos. Participação nas novas políticas democráticas em São Paulo. In : AVRITZER, L. (org.). Participação política em São Paulo. São Paulo : UNESP.

JORDAN, G. \& SCHUBERT, K. 1992. A Preliminary Ordering of Policy Network Labels. European Journal of Political Research, v. 21, n. 1-2, p. 7-27.

KENIS, P. \& SCHNEIDER, 1989.V. Policy Networks as an Analytical Tool for Policy Analysis. Paper for conference at Max PlanckInstitut, Cologne, at December 4-5. Digit.

LAVALLE, A. G. 2003. Sem pena nem glória. O debate sobre a sociedade civil nos anos 90. Novos Estudos, São Paulo, n. 66, p. 91-109, jul. Disponível em : http://www.cebrap.org.br/ $\mathrm{i} \mathrm{m}$ a g e $\mathrm{n} \mathrm{s} / \mathrm{A} \mathrm{r}$ q u i $\mathrm{v}$ o s / SemPenaNemGloriaNovosEstudos.pdf. Acesso em : 3.maio.2008.

LAVALLE, A. G.; CASTELLO, G. \& BICHIR, R. M. 2004. Quando novos atores saem de cena. Continuidades e mudanças na centralidade dos movimentos sociais. Política \& Sociedade, Florianópolis, v. 3, n. 5, p. 3755 , out. Disponível em : http:// www.periodicos.ufsc.br/index.php/politica/ article/view/1977/1726. Acesso em : 3.maio.2008.

2006. Os bastidores da sociedade civil. Protagonismos, redes e afinidades no seio das organizações civis. Versão preliminar. São Paulo : Centro Brasileiro de Análise e Planejamento. Disponível em : http:// www.centrodametropole.org.br/pdf/2006/ Os_Bastidores_28novembro2006.pdf. Acesso em : 3.maio.2008.

LAVAlle, A. G.; HOUTZAGER, P. P. \& CATELLO， G. 2006a. Democracia, pluralização da representação e sociedade civil. Lua Nova, São Paulo, n. 67, p. 49-103. Disponível em : http://www.scielo.br/pdf/ln/ n67/a04n67.pdf. Acesso em : 3.maio.2008.

2006b.Representação política e organizações civis. Novas instâncias de mediação e os desafios da legitimidade. Revista Brasileira de Ciências Sociais, São Paulo, v. 21, n. 60, p. 43-66, fev. Disponível em : http:// www.scielo.br/pdf/rbcsoc/v21n60/29760.pdf. Acesso em : 3.maio.2008.

MARQUES, E. C. 1999. Redes sociais e instituições na construção do Estado e da sua permeabilidade. Revista Brasileira de Ciências Sociais, São Paulo, v. 14, n. 41, p. 43-67, out. Disponível em : http://www.scielo.br/pdf/ rbcsoc/v14n41/1751.pdf. Acesso em : 3.maio.2008.

2004. Redes sociais, poder e intermediação de interesses nas políticas públicas brasileiras. Artigo apresentado no XXVIII Encontro da Associação Nacional de Pós-Graduação e Pesquisa em Ciências Socais, realizado em Caxambu (Minas Gerais), de 27 a 29 de outubro. Digit.

2006. Redes sociais e poder no Estado brasileiro : aprendizados a partir das políticas urbanas. Revista Brasileira de Ciências Sociais, São Paulo, v. 21, n. 60, p. 15-41, fev. Disponível em : http://www.scielo.br/pdf/ rbcsoc/v21n60/29759.pdf. Acesso em : 3.maio.2008.

MARTELETO, R. M. 2001. Análise de redes sociais - aplicação nos estudos de transferências da informação. Ciência da Informação, Brasília, v. 30, n. 1, p. 71-81, jan.-abr. Disponível em : http://www.scielo.br/pdf/ci/v30n1/ a09v30n1.pdf. Acesso em : 3.maio.2008.

MÜLLER, A. L. 2006. A construção das políticas públicas para a agricultura familiar no Brasil : o caso do Programa de Aquisição de Alimentos. Porto Alegre. Dissertação (Mestrado em Desenvolvimento Rural). Universidade Federal do Rio Grande do Sul. 
NUN, J. 1989. La rebelión del coro : estudios sobre la racionalidad política y el sentido común. Buenos Aires : Nueva Visión.

NYLAND, J. 1995. Issue Network and Nonprofit Organizations. Policy Studies Review, Malden, v. 14, n . 1-2, p. 195-2041, Spring-Summer.

PINTO, C. R. J. 2005. Os múltiplos compromissos de uma jovem senhora : a sociedade civil brasileira em um cenário de crise. Digit.

SADER, E. 1988. Quando novos personagens entraram em cena : experiências, falas e lutas dos trabalhadores da Grande São Paulo (19701980). Rio de Janeiro : Paz e Terra.

SADER, E. \& PAOLI, M. C. 1986. Sobre “classes populares" no pensamento sociológico brasileiro. In : CARDOSO, R. C. L. (org.). A aventura antropológica : teoria e pesquisa. Rio de Janeiro : Paz e Terra.

SANTOS, B. S. (org.). 2002. Democratizar a democracia : os caminhos da democracia participativa. Rio de Janeiro : Civilização Brasileira.

SCHERER-WARREN, I. 2006. Das mobilizações às redes de movimentos sociais. Sociedade $e$ Estado, Brasília, v. 21, n. 1, p. 109-130, jan.abr. Disponível em : http://www.scielo.br/pdf/ se/v21n1/v21n1a07.pdf. Acesso em : 3.maio. 2008

SILVA, M. K. 2001. Construção da "participação popular" : análise comparativa de processos de participação social na discussão pública do orçamento em municípios da Região Metropolitana de Porto Alegre/RS. Porto Alegre. Tese (Doutorado em Sociologia). Universidade Federal do Rio Grande do Sul.

2003. A expansão do orçamento participativo na Região Metropolitana de Porto Alegre. In : AVRITZER, L. \& NAVARRO, Z. (orgs.). A inovação democrática no Brasil. O orçamento participativo. São Paulo : Cortez.

. 2006. Das substâncias às relações : uma proposta teórico-metodológica para a análise dos processos de participação social no Bra- sil. Artigo apresentado no III Congresso da Associação Latino-Americana de Ciência Política, realizado em Campinas (São Paulo), de 4 a 6 de setembro. Digit.

SKOGSTAD, G. 2005. Policy Networks and Policy Communities : Conceptual Evolution and Governing Realities. Paper presented at the Annual Meeting of the Canadian Political Science Association. Workshop on "Canada's Contribution to Comparative Theorizing”, occurred at Ontario. Disponível em : http:// ww w.c psa-acs p.ca/papers-2005/ Skogstad.pdf. Acesso em : 3.maio.2008.

STEINER, P. 2006. A Sociologia Econômica. São Paulo : Atlas.

STEPAN, A. 1985. State Power and the Strength of Civil Society in the Southern Cone of Latin America. In : EVANS, P.; RUESCHEMEYER, D. \& SKOCPOL, T. (eds.). Bringing the State Back In. Cambridge : Cambridge University.

TATCHER, M. 1998. The Development of Policy Network Analyses. Journal of Theoretical Politics, London, v. 10, n. 4, p. 389-416.

TELLES, V. 1988. Anos 70 : experiências, práticas e espaços políticos. In : KOWARICK, L. (org.). As lutas sociais e a cidade : São Paulo passado e presente. Rio de Janeiro : Paz e Terra.

WAARDEN, F. V. 1992. Dimensions and Types of Policy Networks. European Journal of Political Research, London, v. 21, n. 1-2, p. 29-52.

WARREN, M. 2005. Citizen Representatives : Mobilizing Representation Forty Years After Pitkin. Paper presented at the Annual Meeting of the American Political Science Association, occurred at Washington, D. C., September $1^{\text {st }}$. Digit. Disponível em : http:// w w w. a l la c a d e m i c.co m/ me ta / p74648_index.html. Acesso em : 3.maio.2008.

WASSERMAN, S. \& FAUST, K. 1994. Social Network Analysis : Methods and Applications. Structural Analysis in the Social Sciences. V. 8. Cambridge : Cambridge University. 
SOCIAL ACTORS AND ATTEMPTS TO BROADEN DEMOCRACY: SOCIAL NETWORKS IN PERSPECTIVE

\section{Joana Tereza Vaz de Moura and Marcelo Kunrath Silva}

ABSTRACT: Over the course of the 1980s and 1990s, Brazil has witnessed the proliferation of forums, councils, committees and partnerships that have instituted institutional channels open for the political expression of actors and segments of civil society at the different levels of government and over a wide range of areas of State action. Nonetheless, the literature that analyzes this process has, to a large extent, adopted a dichotomous and normative view of civil society. We put forth a need to break with static and substantialist views of civil society, through adoption of a processbased and relational approach allowing us to analyze the process that constructs social actors in their relation to other actors and institutions (particularly, with the political and institutional field). Thus, the present paper represents more of a theoretical and methodological proposal than a presentation of research results. Our goal is to look critically at the literature that employs a normative and stylized approach to civil society and propose the incorporation of a political networks approach for the discussion and analysis of processes of formation and engagement of actors from civil society and -more specifically - of how these processes are related to institutional spaces of participation.. As an instrument for methodological operationalization of the 'political networks approach, we propose social network analysis. This method of analysis permits the apprehension of the processes of formation and engagement of actors from civil society through their belonging to a relational and dynamic space where actors with distinct institutional connections (civil society, the State, the market) can be found.

KEYWORDS: participation; social network analysis; process-based and relational approaches; civil society.

\section{ACTEURS SOCIAUX DANS DES ESPACES D’ÉLARGISSEMENT DE LA DÉMOCRATIE : LES RÉSEAUX SOCIAUX EN PERSPECTIVE}

\section{Joana Tereza Vaz de Moura et Marcelo Kunrath Silva}

Au cours des années 1980 et 1990, le Brésil a assisté à la multiplication de forums, conseils, comités et partenariats qui instauraient, dans les divers niveaux du gouvernement et dans les plus divers domaines d'intervention de l'État, des canaux institutionnels ouverts à l'expression politique des acteurs et des segments de la société civile. Pourtant, la littérature qui analyse ce processus a, en général, adopté une vision dichotomique et normative de la société civile, à partir de l'adoption d'un regard processuel et relationnel permettant d'analyser le processus de construction des acteurs sociaux dans leur rapport avec les autres acteurs et institutions (particulièrement, avec la partie politico-institutionnelle). Ainsi, voici un travail de proposition théorico-méthodologique et non pas un travail de présentation de résultats de recherche, qui a pour objectif de mettre en question la littérature qui travaille une approche normative et caricaturale de la société civile et de proposer l’intégration de l'approche des réseaux de politiques au débat et à l'analyse des processus de formation et d'action des acteurs de la société civile et, plus particulièrement, de vérifier comment ces processus ont des rapports avec les espaces institutionnels de participation. Comme outil d'opérationalisation méthodologique de l'approche des réseaux de politiques, nous proposons l'emploi de l'analyse de réseaux sociaux, pour saisir le processus de construction et d'action des acteurs sociaux à partir de leur liaison avec un espace relationnel et dynamique, dans lequel s'insèrent des acteurs à multiples liens intitutionnels (société civile, État, marché).

MOTS-CLÉS: participation ; analyse de réseaux sociaux ; regard processuel et relationnel ; société civile. 